\title{
Working
}

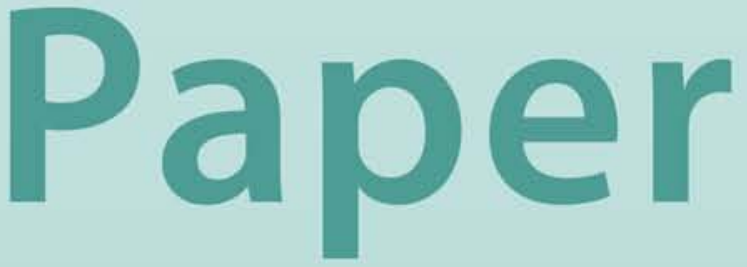


Treating Intangible Inputs as Investment Goods: The Impact on Canadian GDP

Nazim Belhocine 


\title{
IMF Working Paper
}

Western Hemisphere Department

\section{Treating Intangible Inputs as Investment Goods: The Impact on Canadian GDP}

\author{
Prepared by Nazim Belhocine ${ }^{1}$
}

Authorized for distribution by Charles F. Kramer

November 2009

\begin{abstract}

\section{This Working Paper should not be reported as representing the views of the IMF.}

The views expressed in this Working Paper are those of the author(s) and do not necessarily represent those of the IMF or IMF policy. Working Papers describe research in progress by the author(s) and are published to elicit comments and to further debate.

This paper constructs a data set to document firms' expenditures on an identifiable list of intangible items and examines the implications of treating intangible spending as an acquisition of final (investment) goods on GDP growth for Canada. It finds that investment in intangible capital by 2002 is almost as large as the investment in physical capital. This result is in line with similar findings for the U.S. and the U.K. Furthermore, the growth in GDP and labor productivity may be underestimated by as much as 0.1 percentage point per year during this same period.
\end{abstract}

JEL Classification Numbers: O47, O33, E22

Keywords: Intangible Capital Goods, Intangible Investment, Growth

Authors E-Mail Address: nbelhocine@imf.org

\footnotetext{
${ }^{1}$ I would like to thank Eric Bartelsman, Allen Head, Peter Howitt, Stephen Kosempel, Huw Lloyd-Ellis, Leonard Nakamura, John Van Reenen, David Weil for helpful comments, Charles Beach, Michael Smith and Ging Wong for their help with the Canadian data sources and seminar participants at "The 2008 World Congress on National Accounts and Economic Measures for Nations" (Washington, D.C.), at the conference "The Role of Human Capital in Economic Growth” (Guelph University), and at Queen's University for their helpful comments and discussions.
} 
Table of Contents

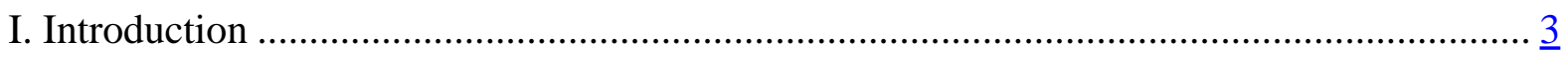

II. National Accounts' Conventions and the Rationale Against it............................................ $\underline{5}$

III. Data Collection Approach...............................................................................................

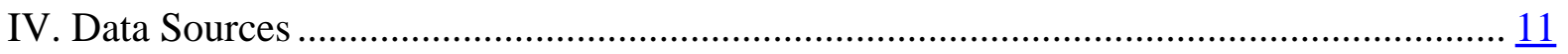

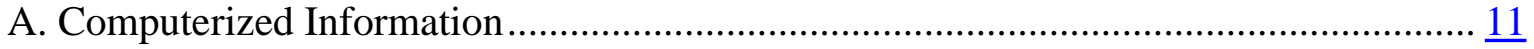

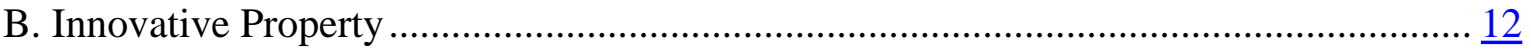

C. Economic Competencies .......................................................................................... 14

V. Summary of Findings and Comparison with Other Countries.......................................... 15

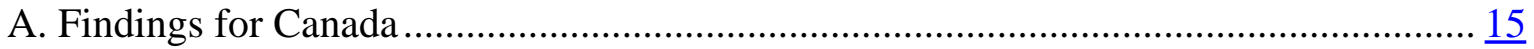

B. Comparison with the U.S. and the U.K....................................................................... $\frac{17}{17}$

VI. Impact of Including Intangibles on GDP................................................................... 18

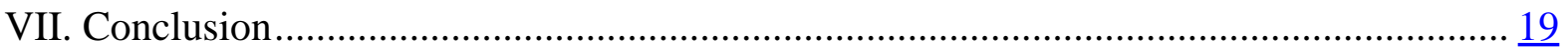

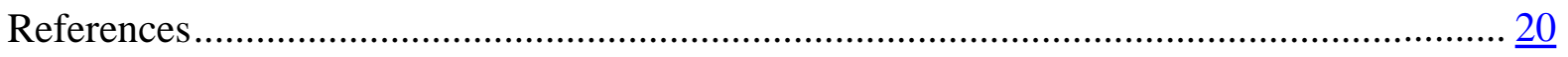

Tables

1. Decomposition of Intangible Expenditures by Item ....................................................... $\frac{16}{18}$

2. Comparison of Expenditures in Intangibles Across U.S., U.K. and Canada........................ $\frac{18}{19}$

3. Impact of Including Intangibles on Real GDP Growth ................................................... 19

Figures

1. Software Investment (overall and by type)...................................................................... 12

2. Tangible Versus Intangible Investment ............................................................................ $\frac{17}{17}$ 


\section{INTRODUCTION}

In the last few years, there has been a growing perception among academics and policymakers that a significant and increasing part of total business investment is directed towards intangible investment. Intangible investment is the expenditure on items which have a knowledge component, such as research and development, training, organizational change, marketing and software. To some researchers, this phenomenon is "what put the new in the new economy" (Nakamura, 1999), while others acknowledge that "although investment in intangible capital is not counted as capital investment in the national income and product accounts, they appear to be quantitatively important.” (Bernanke, 2005)

This paper constructs a data set to document firms' expenditure on a list of intangible items. The approach adopted follows the work of Corrado et al. (2005) where intangible investment is mainly measured at cost. The constructed data set is then used to measure the impact of capitalizing intangible investment, as opposed to expensing it, on GDP growth. It is found that intangible investment averaged 9.6 percent of GDP for the period 1998 to 2004. This investment is as large as the investment in physical capital. This result is in line with similar findings for the U.S. and the U.K. Furthermore, the growth in GDP and labor productivity are found to be underestimated by as much as 0.1 percentage point per year during this same period. In light of current debates at various statistical agencies regarding capitalizing intangibles, this study confirms the need to indeed consider such expenditures as investments and highlights the feasibility of collecting this quantitatively significant investment data as part national income accounts data.

Attempting to take a similar approach applied at various time points during the past 10 years, Baldwin et al. (2005) notice that there are no reliable data in Canada that would give a complete account of expenditures on intangible capital. The lack of reliable data is most likely due to the nature of past surveys: whatever relevant data these surveys collected was likely out of curiosity rather than key elements that would be required by the system of national accounts. Hence, the data in Canada appears to be sparse, often discontinuous and when the data turns out to be almost complete, it is not analyzed in a comprehensive way.

This paper illustrates that the data are rich enough to offer an estimate of the size of intangible investment. The measurement approach used consists of summing up the expenditures and costs involved in producing items that are considered to be intangible. Relying on a specific identification of certain items offers a lower bound for the value of intangibles in two ways: first, it will unlikely exhaust all the components of intangible capital because some non-core items are hard to value (see Vosselman, 1998) and second, the market value of intangible investment goods, in the short-run, can be higher than the cost of their production if there are scarcity rents, for example. Above all, this approach is arguably more reliable because it is not based on backing out the value of intangibles using a tightly specified model as is done in other approaches to measuring intangibles (see in particular Hall, 2001). This latter procedure bears the risk of being contaminated by generating 
intangible quantities and values that are very sensitive to the assumptions adopted; hence, producing estimates that are quite imprecise.

At the root of most investigations into the level of intangible investment lies a dissatisfaction with the practice of national income accountants in treating expenses on intangibles as operating costs. Given that intangibles are assets, they should be capitalized because they are not entirely used up in the production of final output. In this way, they ought to be treated as investment instead of being expensed as intermediate consumption goods (Nakamura, 2003a and Corrado et al. 2005.) This practice by national accountants may have been reasonable when investment in such assets was a negligible portion of total investment. However, that doesn't seem to be the case anymore. If businesses are employing substantial resources to create these intangible assets, it should be possible to discern the impact of these investments on various aspects of the economy. If not, then perhaps the omission is unimportant (Nakamura, 2001a).

Nakamura (1999) was the first to look at the expenditures of firms over time on two important intangible items at the aggregate level, namely R\&D and advertising. His paper points to the increasing share of these intangible items from 1953 until 1997 while tangible investment in plant and equipment was no higher in the 1990s than in the 1950s and 1960s. Nakamura recognizes that it is necessary to account for the spending of firms on other items such as executive time, software and on a wider range of creativity costs to obtain a much clearer picture of intangible investment. This is what Nakamura (2001a) and (2003a) sets out to do: to collect data on the expenditures of firms on R\&D (broadly defined), software, advertising and the like. The author finds that direct and indirect empirical evidence points to an investment in intangibles by U.S. private firms of at least one trillion dollars annually. This amount roughly equals U.S. gross investment in nonresidential tangible assets.

Corrado et al. (2005) build on Nakamura's approach by adopting an intangible classification which comes close to that advocated by OECD statisticians (Vosselman, 1998). They also take an extra step by distinguishing those expenditures that generate long-lasting revenue flows from those whose returns are exhausted too quickly. Corrado et al. (2005) reach the same conclusion as Nakamura (2001a, 2003a); namely that, by 2000, intangible investment was as large as the investment in tangible capital in the U.S. Moreover, they estimate that measured productivity growth increases by .25 percentage points per year between 1995 and 2002 if intangibles are capitalized. In Corrado et al. (2006), the authors follow up on their 2005 paper by extending their data coverage in time and using the investment in intangibles to build a series for the intangible capital stock from 1950 until 2005. This series allows them to conduct a growth accounting exercise and study the impact of capitalizing intangibles on income shares. One of their major findings is that after 1995, capital (both tangible and intangible) deepening surpasses TFP as the principal source of growth.

The work of Corrado et al. (2005) was followed by similar studies conducted for the U.K., France and Germany, Japan and Netherlands respectively, by Marrano and Haskel (2006), 
Hao et al. (2007), Fukao et al. (2007) and van Rooijen-Horsten et al. (2008). These studies reach similar findings in terms of the rise in intangible investment throughout the 1990s. In the U.K., intangible investment reached 10.8 percent of GDP in 2004, a similar level as tangible investment. It is interesting to note that other studies found lower intangible investment levels: 8.3 percent of GDP in Japan between 2000 and 2002 (includes both the private and public sector), 7.6 percent of GDP in France in 2004, 6.5 percent of GDP in Germany in 2004 and 7.5 percent of GDP in Netherlands between 2001 and 2004. To date, no such work has been performed for Canada.

The current state of omission and mismeasurement of intangible capital has several implications. First, because spending on intangibles is not treated as investment, aggregate savings and investment may be significantly understated in official statistics. Monetary policymakers could be misled by such an imprecise picture of the economy in setting interest rates. Second, resource allocation and investment decisions within firms and across firms in a given industry become more difficult. Third, fiscal policy can be affected in various ways such as in the design of a fair tax system. Finally, the lack of good information on intangibles will lead to opaqueness and volatility in capital markets given the increased difficulty of estimating the future cash flows that some investments will generate.

The main contribution of this paper is to quantify the extent to which aggregate investment data is understated in Canada. This will provide a sense of the size of the current omission and how accurate our actual picture of the economy is. The second contribution is to provide more evidence to policy-makers that supports the movement towards the capitalization of intangibles, which is being advocated by many statistical agencies and national accountants.

The rest of the paper proceeds as follows. Section 2 describes the current treatment of intangibles by the national income accounts and develops a framework to advocate against such convention. Section 3 details the methodological approach adopted through a discussion of the data construction. Section 4 reports the data sources and manipulations. Section 5 discusses the findings from the data collection and contrasts the results with similar studies conducted in the U.S. and the U.K. Section 6 investigates the impact of capitalizing intangibles on the growth of GDP. Finally, section 7 concludes with a discussion of future work.

\section{National Accounts’ Conventions and the Rationale Against it}

This section develops a three-sector framework to discuss the current treatment of intangibles by national income accounts and the consequence for GDP of capitalizing intangible 
expenditures. This framework, borrowed from Corrado et al. (2006), also facilitates the discussion that will ensue of the rationale against the current national accounts convention ${ }^{2}$.

There are three sectors in the economy: 1) an intangible investment good sector, 2) a tangible investment good sector and 3) a consumption good sector. All production functions are assumed to be homogeneous of degree one. We also assume that there is perfect competition. These assumptions are necessary to ensure that the compensation of various inputs add up to the value of output. The production function for intangible output, tangible output and consumption goods is given respectively by $\dot{A}=F^{A}\left(L_{A}, K_{A}, A_{A}\right), I=F^{K}\left(L_{K}, K_{K}, A_{K}\right)$ and $C=F^{C}\left(L_{C}, K_{C}, A_{C}\right)$. Each sector $i$ produces its own output using labor $L_{i}$, its accumulated stock of tangibles $K_{i}$ and its accumulated stock of intangibles $A_{i}{ }^{3}$. The tow investment goods accumulate according to

$$
\left\{\begin{array}{l}
K^{\prime}=\left(1-\delta_{K}\right) K+I \\
A^{\prime}=\left(1-\delta_{A}\right) A+\dot{A}
\end{array}\right.
$$

where the prime exponent denotes next period's stock quantity. The revenues for each sector is given by:

$$
\left\{\begin{array}{l}
p^{A} \dot{A}=w L_{A}+r^{K} K_{A}+r^{A} A_{A} \\
p^{I} I=w L_{K}+r^{K} K_{K}+r^{A} A_{K} \\
p^{C} C=w L_{C}+r^{K} K_{C}+r^{A} A_{C}
\end{array}\right.
$$

The aggregate amount of labor, physical capital and intangible capital are defined respectively by $L=L_{A}+L_{K}+L_{C}, K=K_{A}+K_{K}+K_{C}$ and $A=A_{A}+A_{K}+A_{C}$.

In this framework where intangibles are treated as final capital goods, the NIA identity will be written as

$$
\underbrace{p^{Q} Q}_{\text {Value-added approach }}=\underbrace{p^{C} C+p^{I} I+p^{A} \dot{A}}_{\text {Expenditure approach }}=\underbrace{w L+r^{K} K+r^{A} A}_{\text {Income approach }}
$$

where $p^{Q} Q$ is defined as the total value added produced in this economy. The current treatment of intangibles by NIA views them as intermediate inputs. Therefore, NIA implicitly assumes the following identity:

\footnotetext{
${ }^{2}$ Using a different set of assumptions, Howitt (1996) and Nakamura (2003) develop related frameworks where intangibles are treated as investment goods.

${ }^{3}$ For ease of exposition, there are no exogenous sources of TFP growth.
} 


$$
\underbrace{p^{Q} Q-p^{A} \dot{A}}_{\text {Value-added approach }}=\underbrace{p^{C} C+p^{I} I}_{\text {Expenditure approach }}=\underbrace{w L+r^{K} K}_{\text {Income approach }}
$$

An obvious consequence of the current practice by NIA is that GDP and income are undervalued. But why is there such a convention in the first place? The argument often used, to paraphrase Griliches (1994), is that intangibles are "difficult-to-measure goods” for two main reasons ${ }^{4}$ : the first lies in the fact that these goods are rarely exchanged on the market and are mainly produced in-house. As a result, there are no market transactions ${ }^{5}$. This observation has three major implications. The first is that $p^{A}$ becomes a shadow price which needs to be calculated using a specific economic model. The second implication is that the quantity data $\dot{A}$ is difficult to obtain or to separate in the magnitude $p^{A} \dot{A}$. Finally, it is difficult, from an accounting point of view, to verify the truthful and accurate reporting of $p^{A} \dot{A}$, given that $\dot{A}$ is mainly produced inside firms.

The second reason intangibles are difficult to measure is related to the special attributes these goods carry, which are not found in physical investment goods or in consumption goods6. The first attribute is visibility: vintages of the stock $A$ are difficult to observe. This means that the depreciation rate $\delta_{K}$ is difficult to obtain. The second attribute is appropriability. Intangibles create externalities which mean that the measured $p^{A}$ and $r^{A}$ may only reflect private benefits and costs. In other words, they do not accurately reflect the true value or real compensation they deserve. The third attribute is the rivalry characteristic of some of the intangible goods: the marginal cost to produce an extra unit tends to zero, which concretely implies that $p^{A} \approx 0$. The fourth attribute is the fact that intangibles often have the characteristic of a public good: the same quantities are available to all users at the same time. This means that $A \neq A_{A}+A_{K}+A_{C}$ but instead $A=A_{A}=A_{K}=A_{C}$. The fifth attribute is related to uncertainty in the outcome of the production of self constructed goods. Indeed, there is always a positive probability that the production process leads to $\dot{A}=0$. A sixth attribute is that intangibles include elements that are short-lived and some that are long-lived. Concretely, this means that $\delta_{A} \in[0,1]$ (i.e., for some of intangible investment goods, depreciation can be of 100 percent). A final attribute is the lag that can exist between the production of intangibles and their full exploitation.

Do these characteristics provide grounds for the convention of viewing them as expenses as opposed to investment goods? I argue that the answer is no: the issue of expensing versus capitalizing an input should depend on the type of input (capital versus intermediate input)

\footnotetext{
${ }^{4}$ The discussion builds and expands on Corrado et al. (2006) and Nakamura (2001).

${ }^{5}$ What accountants refer to as the existence of an arm's length transaction.
} 
not on: 1) the ease of measurement of the input or 2) the differences in the economic attributes of some inputs.

What distinguishes an intermediate input from a capital good? Capital formation is defined as the expenditure on inputs that will not be consumed by firms in the accounting period. Consumption by firms is the act of using up goods and services in the current period (United Nations (1998)). These "consumed” goods are known as intermediate inputs. Capital is then a produced good "that is used repeatedly or continuously in production over several accounting periods (more than one year)” (United Nations (1998)). A business expenditure that aims to acquire a capital good will be recorded by national income accounts as capital formation only if it is identifiable and if it involves the acquisition of a capital good from the market instead of being produced in-house. ${ }^{6}$ The requirement of identification is met whenever national income accountants can classify the expenditure on the item under a welldefined category of products. On the other hand, the necessity to observe that the item was acquired from the marketplace ensures the existence of an accurate valuation of the good which is captured by the market price.

Given these two requirements and the definition of capital formation, all capital expenditures by firms which are either non-identifiable or are intended to produce a capital good in-house do not end up being recorded as capital formation. The convention in national income accounts is to treat this spending as intermediate consumption expenditure. Consequently, this practice lowers the value added of final produced output and understates the existing stock of capital in the economy.

Research and experimental development (R\&D) expenditures offer a good illustration of the consequence of this convention. Even though national income accounts incorporate data on $R \& D$ spending, this expenditure is treated as an expense rather than an investment mainly because of the lack of a market price on the output of R\&D activities ${ }^{7}$. Training expenses constitute a different example where no data is systematically collected by national income accounts since it is a difficult good to identify or classify.

Intangible investment is believed to have been small before the 1990s, so the issue of their capitalization was seen to be minor. However, both direct and indirect evidence points today for an important share of these expenditures in overall investment. Moreover, given the official definitions of capital goods and intermediate inputs, intangibles have all the

\footnotetext{
${ }^{6}$ Software expenditures are an exception. Since 2001, even when produced in-house, software is treated as capital expenditure (see Statistics Canada (2001)).

${ }^{7}$ Some R\&D spending leads to the creation of a patent which will carry a price if commercialized. However, the market for patents is extremely thin: very few patents change hands. For example, Serrano (2006) documents that only about 20 percent of all U.S. patents issued to small innovators (i.e., firms that were issued no more than five patents in a given year) are traded once or more.
} 
characteristics of capital goods and hence should be collected by national income accounts as investment goods.

\section{Data Collection Approach}

This paper uses a "direct” measurement approach which consists of summing up the expenses and costs involved in purchasing or producing items that are considered to be intangible. A consensus has emerged over time among national income accountants on what those items should be. Vosselman (1998) outlines the core components of intangible investment as: R\&D, education and training, software, marketing, mineral exploration, licenses, brands, copyrights and patents. The supplementary categories of intangible investment are: organizational development, engineering and design, construction and use of databases, remuneration for innovative ideas and other human resource development (training excluded).

In the selection of items for which data will be collected, I follow the categorization of Corrado et al. (2005) of intangible investment. After identifying and listing the items that represent intangible goods, I investigate the sources that might supply data regarding the spending on such goods. The expenditures are then converted into investments by retaining the fraction which will be accumulated over time. Finally, I calculate the new real investment and add it to real GDP in order to calculate the resulting new growth rate.

There are four types of data approaches that are adopted to document the spending of firms on intangibles. The first data that is collected is "bought-in" expenditure data. These data consist of items that have a recorded transaction on the market. These data are typically available if a survey of purchases exists, for example, in the case of prepackaged software. A second approach to collecting data is a consequence of the non-existence of bought-in expenditure data. It consists of gathering the revenue estimates of knowledge-good providers. For example, the revenues of the advertising industry can be used as an approximation for firms' expenditures on advertising. A third type of data that is used stems directly from activities of the firm, which is known as "own-account" spending or "self-constructed" goods. These data are hard to collect without a particular survey, for example, the R\&D surveys. Finally, when all else fails, it is necessary to make an educated guess on the size of some expenditures given certain background information. For example, the own-account spending on organizational change and development is set as 20 percent of the wage of executives by Corrado et al. (2005).

The following is a detailed list of intangibles and their definitions:

\section{Innovative property}

- $\quad$ Scientific R\&D: this item is mainly made of industrial R\&D (science and engineering $\mathrm{R} \& \mathrm{D})$ that usually leads to a patent or a license and can be split into: 
o R\&D conducted in manufacturing, utilities, construction and agriculture.

o Spending for the discovery of new natural reserves through mineral exploration and other geophysical and geological explorations:

- $\quad \mathrm{R} \& D$ expenditures in mining, oil and gas extraction.

- Other geophysical and geological explorations.

- $\quad$ Non-scientific R\&D:

o Information-sector industries: spending for the development of entertainment and artistic originals usually leading to a copyright or license.

o Other new product development: this category encompasses new product development, design and research expenses that do not necessarily lead to a patent or copyright:

- Financial sector : new product development costs in the finance, insurance and real estate industries.

- Other service industries: estimates of $R \& D$ in the remaining services industries.

\section{Computerized information}

- Computerized databases: encompasses the expenditures on data processing activities (processing of data, data entry, data scanning, etc.) and database activities (on-line database publishing, on-line directory publishing, etc.).

- Software: comprises own-account spending on software (software developed inside the firm) and purchased software (either custom made software or general purpose software).

\section{Economic competencies}

- Brand equity: expenditures for the development of brands and trademarks made of two activities:

o Purchased advertising: spending on the acquisition of advertising services.

o Market and consumer research: either conducted inside the firm or purchased from the industry.

- Firms' investment in human capital: or employer-provided training is made of:

o Direct firm expenses on training: in-house trainers, tuition payment, etc. 
o Indirect firm expenses: lost output from employees being trained i.e., the opportunity cost measured as the wage of employees.

- Organizational structure: costs of organizational change and firm development composed of:

o Purchased organizational change and development: typically from the “management consulting” industry.

o Own account: estimated as the dollar value of senior executive time spent on developing business models and corporate cultures.

\section{Data Sources}

This section documents the data sources used for each intangible item. The North American Industrial Classification System (Statistics Canada (2007)) codes were relied upon as much as possible as they allow a very rich and well-defined description of specific items. Also, using these codes will make the data even more comparable across countries, given the international character of the NAICS.

\section{A. Computerized Information}

Computerized information is made of two items: software and computerized databases. I will begin with software. "Software refers in general to the encoded instructions executed by electronic devices, including computers, for performing operations and functions. This includes both systems software and user tools (operating systems, compilers, performance measurement and job accounting tools, etc.) and applications software (word processing, spreadsheets, payroll systems, etc.)" (Jackson (2001)). In 2001, Statistics Canada started producing software data, in conformity with the new SNA 1993 guidelines, and including it in GDP as part of non-residential investment. These data are available today from 1981 until 2007 under the CANSIM series label V3860272. Computer software expenditures are made of own-account spending on software (i.e., developed in-house) and purchased software (either custom-made or pre-packaged). Note that the expenditure on software developed inhouse for firms' own-use is approximated by the wage bill of computer programmers and system analysts. Figure 1 shows the evolution of overall software investment from 1981 to 2000 and the investment in each type of software during this same period. The expenditure on software rose in almost an exponential way. Expenditures on all types have experienced a similar rise although pre-packaged software dominates other types of software expenditures. In 2000, commercial software represented about 45 percent of business expenditures on software with own-account and custom-design software accounting for respectively 25 and 30 percent of total expenditures on software. 
Figure 1. Software Investment (overall and by type)

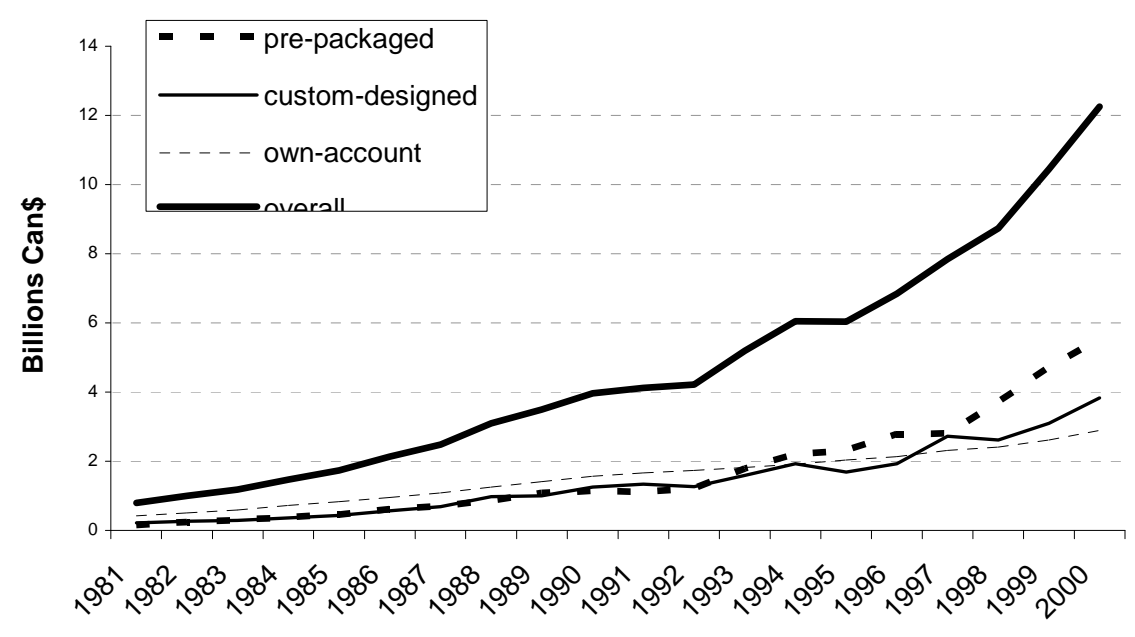

As for the second item, computerized databases, the "Annual Survey of Software Development and Computer Services" collects data on the revenues of firms involved in “data processing, hosting and related services" [NAICS 51821]. The activities covered by the sampled establishments "include specialized hosting activities, such as web hosting, streaming services or application hosting, or may provide general time-share mainframe facilities to clients. Data processing establishments may provide complete processing and preparation of reports from data supplied by the customer; specialized services, such as automated data entry; or they may make data processing resources available to clients on an hourly or time-sharing basis.” (Statistics Canada (2007)). These data are available from 1997 to 2005 under the CANSIM series label V1929941. The own-account spending on computerized databases is likely included in the own-account spending on software given how this latter item is calculated (see former paragraph). As a result, there is no special provision made for the computerized databases developed in-house. Note that the R\&D conducted in this sector is collected as part of the business enterprise research and development (BERD) tables under "information and cultural industries" [NAICS 51]. It is necessary to subtract $\mathrm{R} \& \mathrm{D}$ of data processing companies from their revenues to avoid double-counting. Unfortunately, the R\&D in this sector is inseparable from the broader R\&D of the "information and cultural industries." Given there are 9 sectors within this industry, the $\mathrm{R} \& \mathrm{D}$ of the data processing companies was approximated as one-ninth of the industry's overall R\&D expenditure.

\section{B. Innovative Property}

It is possible to distinguish two broad categories of R\&D: scientific and non-scientific.

The scientific component can be considered as industrial R\&D, an activity which typically leads to a patent. This component is made up of two items. The first item consists of R\&D 
expenditures in manufacturing, utilities and construction and agriculture. These data are collected under the CANSIM vectors V29793132, V29793128, V29793131 and V29793121, respectively. These data are collected as part of the BERD tables and are available by industry group based on NAICS at an annual frequency from 1994 until 2007. Some data observations are missing in some series due to confidentiality agreements. Wherever this problem was encountered, two adjacent observations were used to make an extrapolation.

The second item consists of spending on the discovery of new natural reserves through mineral exploration and other geophysical and geological explorations. It represents R\&D of the "mining, oil and gas extraction" industry, collected as part of BERD and given by the CANSIM vector V29793125, and of “other geophysical and geological exploration.” This latter item is approximated from the output of the surveying and mapping services collected under the "Annual Survey of Service Industries Surveying and Mapping." The corresponding CANSIM vector is V1929009.

Non-scientific R\&D is made up of two large categories: the information-sector industries and other new product development. The information-sector industries are basically the servicesector's R\&D which leads to a copyright. These industries are covered under the umbrella of “information and cultural industries” [NAICS 51]. It includes the publishing industries (including software publishers), motion picture and sound recording industries, broadcasting and telecommunications. This data is collected under the CANSIM vector V29793164. It is necessary to exclude the R\&D of "software publishers" [NAICS 5112] as it has already been counted in software expenditures. Unfortunately, the R\&D of this sector is inseparable from the broader R\&D of the "information and cultural industries.” As mentioned earlier, given there are 9 sectors within this industry, R\&D of software publishers was approximated as one-ninth of the overall R\&D expenditure of this industry.

The second component of the non-scientific R\&D category "other new product development”, consists of the design and research expenses that do not necessarily lead to a patent or copyright. It includes the financial sector, which is made of the finance, insurance and real estate industries [NAICS 52, 53]. Those data are available as part of BERD from 1994 until 2007 under the CANSIM series label V29793165. It also includes all R\&D conducted in the remaining service industries (wholesale and retail trade [NAICS 41, 44-45], transportation and warehousing [NAICS 48-49], architectural and engineering services [NAICS 5413], health care and social assistance [NAICS 62], etc.). These are published by Statistics Canada under the CANSIM label V29793160 (corrected here to omit the financial sector and the information-sector industries). To avoid double-counting with other categories, it is necessary to remove from this series the R\&D conducted by the "computer systems design and related services” [NAICS 5415] and by the "management, scientific and technical 
consulting services” [NAICS 5416] since they are both part of this category of remaining service industries ${ }^{8}$.

\section{Economic Competencies}

The category of economic competencies is made up of three items: brand equity, training and organizational change.

The cost of the development of a brand involves two activities: advertising and market and consumer research. Data on purchased advertising is approximated by the revenues of firms involved in “Advertising and Related Services” [NAICS 5418]. These establishments are primarily engaged in "creating mass-media advertising or public relations campaigns; creating and implementing indoor/outdoor display advertising campaigns, direct mail advertising campaigns and specialty advertising campaigns; placing advertising in media for advertisers or advertising agencies, etc.” (Statistics Canada (2007)). These data have been collected by Statistics Canada from 1997 to 2005 under the "Annual Survey of Advertising and Related Services” and are published under the series label V1927659.

As for the spending on market and consumer research, the data are taken from a 2004 survey of the Canadian market research industry by Datamonitor. The industry "consists of the provision of services involving the collection and analysis of information about consumers, businesses and markets” (Datamonitor (2004)). The report provides the revenues of this industry from 1999 until 2003 with projections as far as 2008. The report notes that 16 percent of the revenues came from the public sector in 2003 . This ratio will be used throughout the period to remove the share of the public sector from the initial data set. The final number is doubled to account for intramural market research following the practice of Corrado et al. (2005).

Training costs consists of direct and indirect expenses. The direct expense is the cost of developing workforce skills (i.e., on-the-job training by in-house trainers, outside trainers, tuition reimbursement for job-related education, and outside training funds). The indirect expenses are made of the opportunity cost of the training activity (i.e., the value of lost output) which is approximated by the wage and salary of employee time spent in formal and informal training. There are no training expenditure data collected by Statistics Canada which made the training cost data overall hard to obtain. As a result, some assumptions had to be made in order to put a dollar value on this activity. The direct firm expenses on training per employee are estimated by the Conference Board of Canada and published in "Learning and Development Outlook 2005” (pp.6) for the years 1996, 1998, 2000, 2002, 2004. These

\footnotetext{
${ }^{8}$ Corrado et al. (2005) have a separate category for R\&D conducted in the social sciences and humanities (firms involved in conducting fundamental and experimental research in economics, sociology, and related fields). It is not possible to single out such category here since R\&D specific to the social sciences and humanities [NAICS 54172] is inseparable from the broader category of "scientific research and development services" [NAICS 5417] which is part of the "other service industries."
} 
expenses are multiplied by the employment data produced by Statistics Canada under the "labor force survey" and given by the label series V2461119. Data for the missing years is extrapolated as an average of the two adjacent years. The indirect data on wage and salary costs of employee time are arbitrarily set at the same amount as the "direct firm expenses." 9

Finally, firms' expenditure on organizational change is estimated by looking at two items. The first item is the portion that is purchased. To proxy these purchased new capabilities, we use the revenue of "management, scientific and technical consulting services" [NAICS 5416] which consists of "management consulting services" [NAICS 54161] and "scientific and technical consulting" [NAICS 54162, 54169]. These data are stored in CANSIM under the series label V1929084 from 1998 to 2005. The second item is the “own account” component estimated as 20 percent of the wage of senior executives by Corrado et al. (2005). This component was only available in the "census of population" data in real terms for the two years 1995 and 2000. These data are collected using the 1991 Standard Occupational Classification and the wage bill used here was the one of "senior management occupations." The wage bill in 2000 was multiplied by 20 percent to obtain an estimate of own account organizational development. The ratio of purchased to own account expenditures in the year 2000 is applied to the amounts purchased in all other years in order to obtain the own account data for the remaining years.

\section{SUMMARY OF FINDINGS AND COMPARISON WITH OTHER COUNTRIES}

\section{A. Findings for Canada}

Table 1 details firms' expenditures on each intangible item as a percentage of the GDP reported by national accounts.

Notice that the shares of each of the major three categories of intangibles in GDP from 1998 to 2004 are quite stable. The share of computerized information is the smallest and comprises about 1.1 percent of the reported GDP. The ratio of spending in the economic competencies category is second in size, with an average of 3.75 percent. Finally, the ratio of the innovative property is the largest, with an average of 4.6 percent.

\footnotetext{
${ }^{9}$ This seems to have been the case for the U.K. in 2004 from the work of by Marrano and Haskel (2006). Corrado et al. (2005) find that indirect costs are 4 times the direct costs between the years 1998-2000.
} 
Table 1. Decomposition of Intangible Expenditures by Item

\begin{tabular}{|c|c|c|c|c|c|c|c|c|}
\hline \multirow[b]{2}{*}{ Type of intangible investment } & \multicolumn{8}{|c|}{ Spending as a \% of Reported GDP } \\
\hline & 1998 & 1999 & 2000 & 2001 & 2002 & 2003 & 2004 & 2005 \\
\hline Computerized information & 1.09 & 1.07 & 1.02 & 1.19 & 1.11 & 1.11 & 1.06 & 1.03 \\
\hline Computer Software & 0.97 & 0.95 & 0.87 & 0.98 & 0.89 & 0.89 & 0.85 & 0.83 \\
\hline Computerized databases & 0.12 & 0.12 & 0.15 & 0.21 & 0.22 & 0.22 & 0.21 & 0.20 \\
\hline Innovative property & 4.30 & 4.35 & 4.49 & 4.72 & 4.78 & 4.80 & 4.83 & 4.97 \\
\hline Scientific R\&D & 1.65 & 1.68 & 1.79 & 1.97 & 1.91 & 1.86 & 1.87 & 1.90 \\
\hline Mineral exploration & 1.04 & 1.03 & 1.00 & 1.08 & 1.10 & 1.06 & 1.09 & 1.11 \\
\hline Non-Scientific R\&D & 1.61 & 1.64 & 1.70 & 1.68 & 1.77 & 1.87 & 1.88 & 1.96 \\
\hline Copyright and license costs & 0.03 & 0.03 & 0.03 & 0.05 & 0.05 & 0.09 & 0.10 & 0.11 \\
\hline New product dvpmt c & 0.01 & 0.01 & 0.01 & 0.02 & 0.02 & 0.02 & 0.02 & 0.03 \\
\hline $\mathrm{R} \& \mathrm{D}$ in remaining service industries & 1.57 & 1.60 & 1.66 & 1.61 & 1.70 & 1.76 & 1.75 & 1.82 \\
\hline Economic competencies & 3.99 & 4.07 & 3.98 & 3.83 & 3.90 & 3.73 & 3.84 & 3.79 \\
\hline Brand equity & 0.56 & 0.54 & 0.54 & 0.54 & 0.52 & 0.48 & 0.48 & 0.50 \\
\hline Advertising expenditure & 0.47 & 0.45 & 0.45 & 0.45 & 0.42 & 0.39 & 0.39 & 0.41 \\
\hline Market research & 0.09 & 0.09 & 0.09 & 0.09 & 0.09 & 0.09 & 0.09 & 0.09 \\
\hline Firm specific human capital & 2.38 & 2.40 & 2.36 & 2.15 & 2.23 & 2.13 & 2.26 & 2.16 \\
\hline Direct firm expenses & 1.19 & 1.20 & 1.18 & 1.08 & 1.11 & 1.06 & 1.13 & 1.08 \\
\hline Wage and salary costs of employee tin & 1.19 & 1.20 & 1.18 & 1.08 & 1.11 & 1.06 & 1.13 & 1.08 \\
\hline Organizational structure & 1.04 & 1.13 & 1.08 & 1.14 & 1.16 & 1.12 & 1.10 & 1.13 \\
\hline Purchased & 0.66 & 0.71 & 0.68 & 0.72 & 0.73 & 0.70 & 0.69 & 0.71 \\
\hline Own account & 0.39 & 0.42 & 0.40 & 0.42 & 0.43 & 0.41 & 0.41 & 0.42 \\
\hline Tota & 9.38 & 9.49 & 9.49 & 9.74 & 9.79 & 9.64 & 9.73 & 9.78 \\
\hline
\end{tabular}

Overall, intangible investment averaged 9.6 percent as a percent of GDP for the period 1998 to 2004. This intangible investment almost matched the investment in physical capital around the year $2002^{10}$. Figure 2 shows the evolution of both tangible and intangible investment. Notice that as tangible investment declines until 2000, intangible investment continues to climb, reaching its peak at almost 10 percent of GDP. After 2001, both forms of investment flatten out, then pick up steam in 2003, albeit at different speeds.

\footnotetext{
${ }^{10}$ Tangible or physical investment is defined as business investment in non-residential structures and equipment as reported by Statistics Canada under the vector V647541. Note that software investment was removed from this vector given it is considered as an intangible investment.
} 
Figure 2. Tangible Versus Intangible Investment

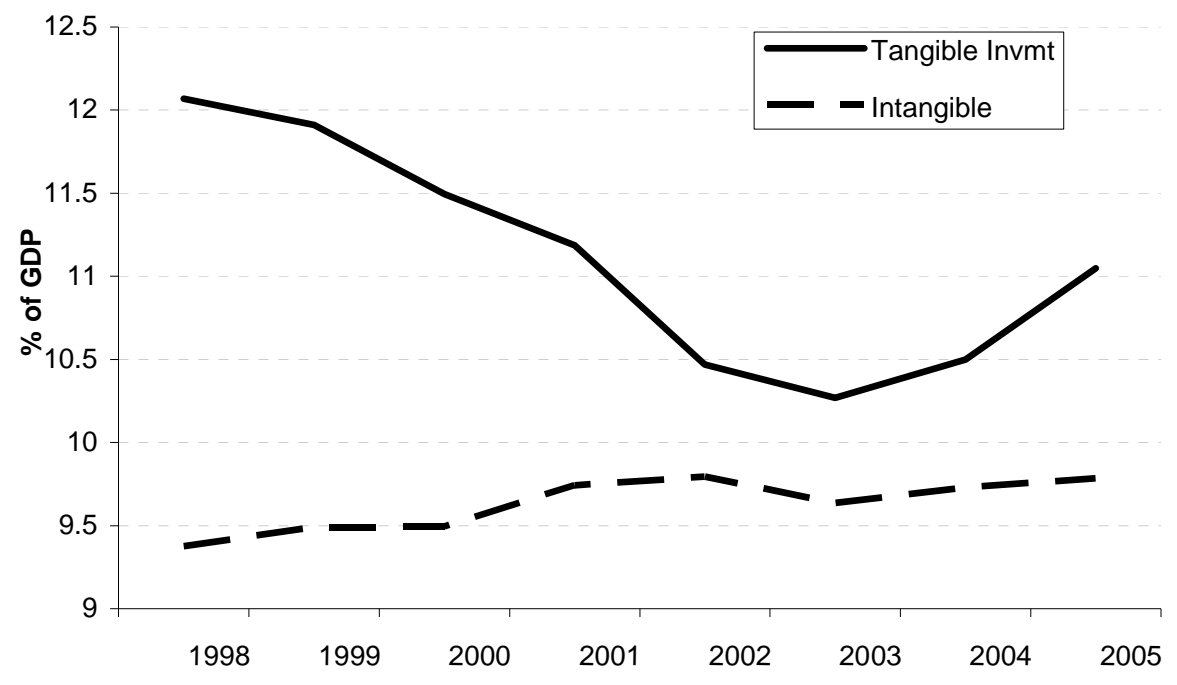

B. Comparison with the U.S. and the U.K.

The findings for Canada are contrasted with the findings for the U.S., by Corrado et al. (2005) for the years 1998-2000, and with the findings for the U.K., by Marrano and Haskel (2006) in 2004. Table 2 shows each category of intangible investment and its share in GDP for each country. As mentioned earlier, the investment in intangibles in Canada almost matches the investment in physical capital in 2002. It is striking to find the same observation in the U.S. and the U.K. However, Canada's investment in intangibles is lower than the U.K. and the U.S., although not far from the level reported for the U.K. This result is mainly driven by a lower investment in economic competencies and in particular, in brand equity and intramural organizational change. 
Table 2. Comparison of Expenditures in Intangibles Across U.S., U.K. and Canada

\begin{tabular}{|c|c|c|c|}
\hline \multirow[b]{2}{*}{ Type of intangible investment } & \multicolumn{3}{|c|}{ Spending as a \% of GDP } \\
\hline & $\begin{array}{c}\text { US } \\
(98-2000) \\
\end{array}$ & $\begin{array}{c}\text { UK } \\
(2004) \\
\end{array}$ & $\begin{array}{r}\text { CAN } \\
(2000) \\
\end{array}$ \\
\hline Computerized information & $1.65 \%$ & $1.70 \%$ & $1.02 \%$ \\
\hline Software: purchased & & $1.70 \%$ & $0.87 \%$ \\
\hline Computerized databases & & & $0.15 \%$ \\
\hline Innovative property & $4.58 \%$ & $3.23 \%$ & $4.49 \%$ \\
\hline Scientific R\&D & $1.98 \%$ & $1.06 \%$ & $1.79 \%$ \\
\hline Mineral exploration & $0.19 \%$ & $0.04 \%$ & $1.00 \%$ \\
\hline Non-Scientific R\&D & $2.41 \%$ & $2.13 \%$ & $1.70 \%$ \\
\hline Copyright and license costs & $0.81 \%$ & $0.21 \%$ & $0.03 \%$ \\
\hline New product dvpmt costs in financial industry & $0.79 \%$ & $0.69 \%$ & $0.01 \%$ \\
\hline New architectural \& engineering designs & $0.73 \%$ & $1.20 \%$ & $1.66 \%$ \\
\hline R\&D in social science and humanities & $0.08 \%$ & $0.03 \%$ & \\
\hline Economic competencies & $6.91 \%$ & $5.94 \%$ & $3.98 \%$ \\
\hline Brand equity & $2.53 \%$ & $1.59 \%$ & $0.54 \%$ \\
\hline Advertising expenditure & $2.33 \%$ & $1.20 \%$ & $0.45 \%$ \\
\hline Market research & $0.20 \%$ & $0.39 \%$ & $0.09 \%$ \\
\hline Firm specific human capital & $1.25 \%$ & $2.44 \%$ & $2.36 \%$ \\
\hline Direct firm expenses & $0.24 \%$ & $1.27 \%$ & $1.18 \%$ \\
\hline Wage and salary costs of employee time & $1.01 \%$ & $1.17 \%$ & $1.18 \%$ \\
\hline Organizational structure & $3.13 \%$ & $1.91 \%$ & $1.08 \%$ \\
\hline Purchased & $0.87 \%$ & $0.60 \%$ & $0.68 \%$ \\
\hline Own account & $2.26 \%$ & $1.31 \%$ & $0.40 \%$ \\
\hline Total & $13.14 \%$ & $10.87 \%$ & $9.49 \%$ \\
\hline
\end{tabular}

\section{IMPACT OF INCLUDING INTANGIBLES ON GDP}

It is important to explore the consequence of the omission of intangibles not only on aggregate investment but on real GDP growth. Table 3 reports the growth rates of real GDP with and without intangible investment and the resulting discrepancy.

Overall intangible spending from 1998 to 2004 was deflated by the GDP deflator to obtain the real intangible spending of firms. The resulting series obtained is added to real GDP and the new growth rate of GDP is calculated and then compared to that obtained without intangibles. I find that real GDP growth in Canada is, on average, understated by 0.1 percentage point per year for the period considered with a standard deviation of 0.23 percentage points. The period from 1999 to 2001 experienced an under-estimation while the period from 2002 to 2003 were over-estimated. In comparison, Corrado et al. (2005) find 
that U.S. GDP growth is underestimated by about 0.25 percentage point per year during a similar period.

Table 3. Impact of Including Intangibles on Real GDP Growth

\begin{tabular}{cccc} 
Year & $\begin{array}{c}\text { GDP growth with } \\
\text { intangibles }\end{array}$ & $\begin{array}{c}\text { Reported GDP } \\
\text { growth }\end{array}$ & Discrepancy \\
\hline 1999 & $5.87 \%$ & $5.53 \%$ & $0.34 \%$ \\
2000 & $5.26 \%$ & $5.23 \%$ & $0.03 \%$ \\
2001 & $2.03 \%$ & $1.78 \%$ & $0.25 \%$ \\
2002 & $2.87 \%$ & $2.94 \%$ & $-0.07 \%$ \\
2003 & $1.53 \%$ & $1.82 \%$ & $-0.29 \%$ \\
2004 & $3.44 \%$ & $3.30 \%$ & $0.14 \%$ \\
\hline
\end{tabular}

\section{CONCLUSION}

This paper follows a direct approach to document firms' expenditures on an identified list of intangible inputs for which there is now wide agreement among national accountants. The implications of treating intangible spending as an acquisition of final (capital) goods on GDP growth for Canada were then examined. Intangible investment averaged 9.6 percent of GDP per year for the period 1998 to 2004 and was found to be almost as large as the investment in physical capital around the year 2002. This result is in line with similar findings for the U.S. and the U.K. However, Canada's investment in intangibles is slightly lower than the U.K. and quite a bit lower than the U.S. Finally, I find that the growth in GDP and labor productivity may be underestimated by as much as 0.1 percentage point per year during this same period. The discussion on the need to capitalize intangibles and the magnitude of the findings demonstrate the necessity to report such expenditures as investments and to collect this data as an integral part of the system of national income accounts.

For future research, I plan to extend the period covered from 1980 to 1998. The data for this period is even sparser and requires better consolidation. The goal is to conduct a growth accounting exercise to measure the implication on TFP measurement of the omission of intangibles in the estimates of the overall capital stock. Related to this, a second research direction is to use the investment data on intangibles to calculate the stock of intangibles in the Canadian economy. This will involve making compromises regarding which appropriate depreciation rate and price of capital to use. As shown in Belhocine (2007), there is evidence that the behavior of the price of intangibles is drastically different from the behavior of the price of physical capital goods or of consumption goods. Finally, one dimension that was not studied and discussed in this paper is the implication of the capitalization intangibles on the income side of the national income identity. The income shares of the inputs will be affected in a non-trivial way. With a longer data set, it will be useful to examine how the pattern of these shares changed and draw conclusions regarding the winners and losers of the increasing share of intangibles in overall investment. 


\section{References}

Baldwin, J. R., D. Beckstead, and D. Gelatlly, "Canada's investments in science and innovation: is the existing concept of R\&D sufficient? ," Research Paper Series, Statistics Canada., 2005, Catalogue no. 11F0027MIE - No.032.

Belhocine, Nazim, "The Embodiment of Intangible Investment Goods: a q-theory Approach,” Working Paper, Queen’s University, 2008.

Bernanke, Ben, “Remarks,” Feb 2005. made at the C. Peter McColough Roundtable Series on International Economics Council on Foreign Relations, University of Arkansas at Little Rock Business Forum, Little Rock, Arkansas. Federal Reserve Board.

Corrado, Carol, Charles Hulten, and Daniel Sichel, "Measuring Capital and Technology: An Expanded Framework," in C. Corrado, J. Haltwinger, and D. Sichel, eds., Measuring Capital in the New Economy, Vol. 65 2005, pp. 11-41.

- , - and - "Intangbile Capital and Economic Growth," NBER Working Paper No. 11948, 2006.

Datamonitor, "MArket Research in Canada," Industry Profile, 2004, Reference Code 00700761.

Fukao, Kyoji, Hamagata Sumio, Miyagawa Tsutomu, and Tonogi Konomi, "Intangible Investment in Japan: Measurement and Contribution to Economic Growth," RIETI Discussion Paper Series 07-E-034, 2007.

Griliches, Zvi, "Productivity, R\&D, and the Data Constraint,” American Economic Review, 1994, 94 (2), 1-23.

Hall, Robert E., "The Stock Market and Capital Accumulation," American Economic Review, 2001, 91 (5), 1185-1202.

Hao, Janet Xiaohui, Vlad Malone, and Bart van Ark, "Intangilbe Capital and Growth An International Comparison of France, Germany, Netherlands, United Kingdom and the United States,” Working Paper, The Conference Board, New York., 2007.

Howitt, Peter, “On Some Problems in Measuring Knowledge-Based Growth,” in Peter Howitt, ed., Measuring Capital in the New Economy, 1996, pp. 9-29.

Jackson, Chris, "Capitalization of Software in the National Accounts," Research Paper Series, Stat Canada, 2001. 
Marrano, Mauro G. and Jonathan Haskel, "How Much Does the UK Invest in Intangible Assets? ,” Working Paper No. 578, Queen Mary, University of London, 2006.

Nakamura, Leonard I., "Intangibles: What Put the New in the New Economy? ," Business Review. Federal Reserve Bank of Philadelphia., July/August 1999.

- , "What is the U.S. Gross Investment in Intangibles? (At Least) One Trillion Dollars a Year! ,” Working Paper No. 01-15, Federal Reserve Bank of Philadelphia., 2001a.

- , "Investing in Intangibles: Is a Trillion Dollars Missing from GDP? ,” Business Review. Federal Reserve Bank of Philadelphia., Fourth Quarter 2001b.

- , “A Trillion Dollars a Year in Intangible Investment and the New Economy,” in John R.M. Hand and Baruch Lev, eds., Intangible Assets, 2003a, pp. 19-47.

- , “The Rise in Gross Private Investment in Intangible Assets Since 1978,” Working Paper, Federal Reserve Bank of Philadelphia., 2003b.

Serrano, J. Carlos, “The Dynamics of the Transfer and Renewal of Patents," Working Paper, University of Toronto, 2006.

Statistics, Canada, Capitalization of Software in the National Accounts, Vol. 13-605-XIE, Statistics Canada. Ottawa, Version updated June 20072001.

- , North American Industry Classification System (NAICS) - Canada, Vol. 12-501XIE2007001, Statistics Canada. Ottawa, 2007.

United Nations, National Accounts Statistics: Main Aggregates and Detailed Tables, United Nations Publications, 1998.

van Rooijen-Horsten, Myriam, Dirk van den Bergen, and Murat Tanriseven, "Intangible Capital in the Netherlands: A Benchmark," Discussion paper (08001), Statistics Netherlands, 2008.

Vosselman, Wim, "Initial Guidelines for the Collection and Comparison of Data on Intangible Investment,” Working Paper, Organization for Economic Cooperation and Development, Paris, 1998. 